\title{
Advances in Diagnosis and Treatment of Latent Tuberculosis Infection
}

\author{
Helena J. Chapman, MD, MPH, and Michael Lauzardo, MD, MSc
}

In the United States, latent tuberculosis infection (LTBI) affects between 10 and 15 million people, of whom $10 \%$ may develop active tuberculosis disease. People at increased risk for tuberculosis reactivation include recent immigrants from countries with a high incidence of tuberculosis, children younger than age 5, people who have been infected with Mycobacterium tuberculosis within the past 2 years, or people with immunosuppression for a variety of reasons. Appropriate diagnosis and treatment of LTBI are critical for controlling and eventually eliminating tuberculosis as a public health problem. Although the tuberculin skin test is the traditional diagnostic measure for LTBI, reduced specificity has promoted the development and utilization of the interferon- $\gamma$ release assays as an in vitro blood test with specific antigens to M. tuberculosis (QuantiFERON-TB Gold In-Tube test and the T.SPOT-TB test are commercially available). Despite the rise of the new diagnostic tests, however, there is still no gold standard for diagnosing LTBI, and epidemiologic risks and comorbidities need to be taken into account before initiating therapy. Current diagnostic tests combined with recommended treatment regimens are valuable tools that, when used correctly, promise to hurry the elimination of tuberculosis. ( $\mathrm{J}$ Am Board Fam Med 2014;27:704-712.)

Keywords: Infectious Diseases, Respiratory Tract Diseases

Historically known as a leading cause of global mortality, there has been a dramatic $41 \%$ reduction in the rates of mortality from tuberculosis (TB) and a $36 \%$ in prevalence over the past 2 decades. ${ }^{1}$ In 2012, with an estimated 8.6 million new TB cases and 1.3 million TB fatalities across the globe, the health and economic burden of active TB disease remains elevated in low- and middle-income countries. $^{2,3}$ In addition, because there are approximately 2 billion people with latent or asymptomatic Mycobacterium tuberculosis infection, the increased

This article was externally peer reviewed.

Submitted 11 February 2014; revised 4 June 2014; accepted 6 June 2014.

From the Southeastern National Tuberculosis Center, Division of Infectious Diseases and Global Medicine, University of Florida College of Medicine, Gainesville (HJC, $\mathrm{ML})$; and the Department of Environmental and Global Health, University of Florida, Gainesville (HJC).

Funding: This manuscript was funded by the University of Florida Research Foundation, Inc.

Conflict of interest: none declared.

Corresponding author: Helena Chapman, MD, MPH, Southeastern National Tuberculosis Center, Division of Infectious Diseases and Global Medicine, University of Florida College of Medicine, PO Box 103600, Gainesville, Florida 32610 (E-mail: Helena.Chapman@medicine.ufl.edu). risk of progression to TB disease is a major global health concern. ${ }^{4}$

M. tuberculosis is transmitted through aerosol droplets from a person with active pulmonary TB disease. ${ }^{5}$ An estimated $10 \%$ of individuals who inhale the aerosol droplets develop active TB disease at some point during their lifetime; the greatest risk of this is during the first 2 years after initial exposure. ${ }^{6}$ However, immunocompromised individuals have a larger risk of $\mathrm{TB}$ reactivation, including up to $10 \%$ increased annual risk for people positive for the human immunodeficiency virus (HIV). ${ }^{7}$ Of the remaining $90 \%$ of individuals who become infected, the organism remains dormant in the body, producing an asymptomatic latent TB infection (LTBI). ${ }^{8}$ Key differences between active infections and LTBIs ${ }^{2,4,5,7,9-11}$ are listed in Table 1 .

In the United States, between 10 and 15 million people- or $3.2 \%$ of the population-are estimated to have an LTBI. ${ }^{7,12}$ Over the past 2 decades, the incidence trend in active TB disease has decreased in the United States from 14,874 new cases in $2003^{13}$ to 13,293 new cases in $2007^{14}$ and then to 9,951 new cases in 2012. ${ }^{15}$ Specific groups that 


\begin{tabular}{|c|c|c|}
\hline & Active & Latent \\
\hline \multicolumn{3}{|l|}{ Estimated numbers, 2012} \\
\hline Global $^{2,4}$ & 8.6 million people per year; 1.3 million deaths per year & 2 billion people \\
\hline United States $^{7,9,10}$ & 9,945 tuberculosis cases (rate of 3.2 cases per 100,000 people) & 10 to 15 million people \\
\hline \multirow[t]{2}{*}{ Clinical presentation $^{4,5}$} & Usually symptomatic & Asymptomatic \\
\hline & $\begin{array}{l}\text { Depends on primary disease, but usually includes persistent } \\
\text { cough ( }>2 \text { weeks); fever; night sweats; unexplained weight } \\
\text { loss; fatigue; dyspnea; hemoptysis; chest pain; pleuritic pain }\end{array}$ & \\
\hline Chest radiograph ${ }^{4,11}$ & $\begin{array}{l}\text { Usually abnormal radiographic imaging } \\
\text { Depends on primary disease, but usually includes the } \\
\text { following: } \\
\text { - If primary (recent) infection: middle or lower lobe } \\
\text { infiltrates, ipsilateral hilar adenopathy, or cavitation } \\
\text { - If secondary (reactivation) infection: upper lobe infiltrates or } \\
\text { cavitation } \\
\text {-If healed (previous) infection: hilar or upper lobe dense } \\
\text { pulmonary nodules, with or without visible calcification }\end{array}$ & Normal radiographic imaging \\
\hline
\end{tabular}

have increased risk of reactivation of LTBI to active TB disease include foreign-born people with previous TB infection (within 2 years) that was not treated or treated ineffectively; immunosuppressed people (e.g., HIV, head or neck cancer, chronic renal disease, diabetes mellitus); people with previous gastrointestinal surgical procedures (e.g., gastrectomy, jejunoileal bypass); people taking immunosuppressive treatment (e.g., tumor necrosis factor- $\alpha$ antagonists, chronic corticosteroid use, therapy after organ transplantation); people with poor nutrition status; or children $<5$ years old. ${ }^{12,16,17}$ Groups at high risk for LTBI should be identified to diagnosis and treat these infections. ${ }^{18}$

\section{Diagnostic Tools in LTBI \\ Tuberculin Skin Test}

For over a century, the tuberculin skin test (TST), or Mantoux test, was the only screening tool for LTBI. ${ }^{19}$ A $0.1 \mathrm{~mL}$ purified protein derivative of $M$. tuberculosis-secreted proteins is intradermally injected into the volar surface of the forearm, and a positive or negative delayed-type hypersensitivity reaction is evaluated (as millimeters of induration) after 48 to 72 hours. ${ }^{20}$ If a baseline assessment is required for TST, especially for those people who receive annual TST testing (e.g., health care workers), and a possible immunologic "boost" to the injection, then the sequential 2-step testing, or a second TST, would occur following an initial negative TST. ${ }^{21}$ Because annual TST testing may introduce the Mycobacterium antigens for recognition by the immune system, this immunologic "boost" may produce a reaction upon TST administration, which is indicative of previous positivity and not necessarily recent conversion. ${ }^{9,21}$

Although the TST is an inexpensive diagnostic tool without laboratory analysis with clear definitions for interpretation, the intradermal administration and interpretation must be completed by experienced clinicians. ${ }^{22}$ Patients must return to the clinic within 48 to 72 hours to receive the final interpretation of the test. ${ }^{23}$ The test has low specificity, causing false positives in patients who had a previous history of the bacilli Calmette-Guérin (BCG) vaccination or exposure to nontuberculous mycobacteria (NTM). ${ }^{24,25}$ It has low sensitivity in some populations, causing false negatives in immunocompromised patients with HIV infection, systemic infections, and chronic renal disease; people with prior gastrointestinal surgical procedures; people who had a live vaccination within the previous 2 months; people who are malnourished; or people taking systematic immunosuppressive medications. ${ }^{11,12}$

\section{Interferon- $\gamma$ Release Assays}

Interferon- $\gamma$ release assays (IGRAs) were developed to address the shortcomings of the TST. These in vitro blood tests assess the immunologic reaction of cytokines (interferon- $\gamma$ ) to specific antigens to M. tuberculosis. ${ }^{26}$ The QuantiFERON-TB test (QFT) and the QFT Gold test (QFT-G) (Cellestis Ltd, Carnegie, Victoria, Australia) became available and approved by the US Food and Drug Administration in 2001 and 2005, respectively. ${ }^{27,28}$ 
After the Centers for Disease Control and Prevention (CDC) revised the 2005 guidelines on IGRAs, QFT-G In-Tube test (Qiagen, Valencia, CA) was approved in 2007 to evaluate the response to $M$. tuberculosis-specific antigens (CFP-10, ESAT-6, TB7.7) when compared with control media. $^{29,30}$ In 2008, the T.SPOT TB test (Oxford Immunotec, Abingdon, UK) was developed, requiring $5 \mathrm{~mL}$ of peripheral mononuclear cells for the enzyme-linked immunospot to evaluate the response to $M$. tuberculosis-specific antigens (CFP-10, ESAT-6) when compared with control media. ${ }^{31}$ Results for the QFT-G In-Tube and T-SPOT.TB tests are recorded with qualitative (positive, negative, or indeterminate) and quantitative values within a period of 24 hours. ${ }^{28,30}$ Key differences between the TST and IGRA as diagnostic measures for LTBI $^{21,23,30,32,33}$ are listed in Table 2.

\section{Current Diagnostic Recommendations}

Although the prevalence of TB in the United States has decreased approximately $63 \%$ in the past 2 decades (3.2 TB cases per 100,000 people in $2012^{34}$ ), current diagnostic recommendations conclude that IGRAs permit several advantages over the TST in clinical practice. ${ }^{7,12,23,35-39}$ Because IGRAs have specific antigens that target $M$. tuberculosis, they do not react with common $\mathrm{NTM}^{23,39}$ or BCG vaccine strains ${ }^{12,36}$ and do not produce an immunologic "boost." ${ }^{40,41}$ Although there are additional costs, the administrative and laboratory analytical techniques for IGRAs follow a standard, objective protocol and provide results within 24 hours, enabling the identification and management of patients with LTBI from hardto-reach groups. ${ }^{42}$

IGRAs have been recommended as tests in the diagnosis of $M$. tuberculosis infection in several different clinical scenarios. ${ }^{37,38,43}$ IGRAs should be administered in adults, including BCG-vaccinated individuals $s^{37,38}$ or people with immunocompromising conditions. ${ }^{23,44}$ They should also be administered in situations where the TST has a positive result or in hard-to-reach population groups. ${ }^{42,45}$ In addition, IGRAs may be considered in children $>5$ years old who have a suspected LTBI, whether from a high-incidence country or with confirmed household contacts. ${ }^{42,46}$ However, another physician with expertise in the diagnostics and management of TB should review any clinical case where a child with an immunocompromising condition presents with a suspected LTBI. ${ }^{42}$

However, there may arise clinical scenarios in which IGRA diagnostic measures conclude a qualitative result as indeterminate or a quantitative value in the borderline zone after testing patients with a suspected diagnosis of LTBI. When IGRA results are near the cutoff points, which is consid-

Table 2. Key Differences Between Tuberculin Skin Test (TST) and Interferon- $\gamma$ Release Assay (IGRA) as Diagnostic Measures for Latent Tuberculosis Infection

\begin{tabular}{|c|c|c|}
\hline Characteristics & TST & IGRA \\
\hline Protocol $^{23,30}$ & $\begin{array}{l}\text { After the } 0.1-\mathrm{mL} \text { intradermal injection of PPD of } \\
\text { Mycobacterium antigens into the patient, the } \\
\text { area is measured between } 48 \text { to } 72 \text { hours for } \\
\text { size of induration }\end{array}$ & $\begin{array}{l}\text { After taking a } 3 \text { - to } 5-\mathrm{mL} \text { sample of peripheral } \\
\text { blood mononuclear cells from the patient, } \\
\text { the response of IFN- } \gamma \text { production by T- } \\
\text { lymphocytes upon stimulation with specific } \\
\text { Mycobacterium tuberculosis antigens (CFP-10, } \\
\text { ESAT-6, TB7.7) is measured within } 24 \\
\text { hours }\end{array}$ \\
\hline Estimated sensitivity ${ }^{21,32}$ & $\begin{array}{l}75 \% \text { to } 90 \% \text { (reduced in immunocompromised } \\
\text { patients) }\end{array}$ & $78 \%$ to $92 \%$ \\
\hline Estimated specificity ${ }^{21,32}$ & $\begin{array}{l}70 \% \text { to } 95 \% \text { (reduced in BCG-vaccinated and } \\
\text { NTM infections) }\end{array}$ & $93 \%$ to $98 \%$ \\
\hline Advantages ${ }^{23,33}$ & No laboratory procedures or costs & $\begin{array}{l}\text { May be more cost-effective } \\
\text { Requires one visit } \\
\text { Objectivity in test interpretation }\end{array}$ \\
\hline Disadvantages $^{32}$ & $\begin{array}{l}\text { Requires follow-up visit ( } 48 \text { to } 72 \text { hours later) } \\
\text { High subjectivity in test interpretation }\end{array}$ & $\begin{array}{l}\text { Requires laboratory procedures } \\
\text { Should not be used in children }<2 \text { years of } \\
\text { age because of limited data in children } \\
\text { between } 2 \text { and } 4 \text { years of age }\end{array}$ \\
\hline
\end{tabular}

BCG, Bacillus Calmette-Guérin; IFN, interferon; NTM, nontuberculous mycobacteria; PPD, purified protein derivative. 
ered the borderline zone, the test results should be cautiously considered in combination with the clinical evaluation. ${ }^{47,48}$ However, if IGRAs produce an indeterminate or invalid result, whether low mitogen or high Nil (negative control), the tests should be repeated and reviewed by a TB specialist. ${ }^{30}$

\section{Current Gaps in Diagnostic Measures}

The definitive diagnosis of LTBI is complicated and requires a case-by-case review. There is no current gold standard diagnostic measure ${ }^{32,49}$ or ability to directly diagnose LTBI with radiographic imaging ${ }^{11}$ or serum biomarkers. ${ }^{50}$ The current diagnostic tools of TST and IGRAs cannot distinguish between evidence of prior TB disease or present active TB disease. ${ }^{51}$

Future studies should target the accuracy of LTBI diagnostic testing in high-risk populations. First, because the host immunologic response is key to the IGRA response, people with immunocompromising conditions, such as autoimmune diseases, end-stage renal disease, or after transplantation, require a more cautious evaluation of diagnostic tests. ${ }^{23,35,52}$ Second, the TST is preferred over IGRA as the diagnostic tool in children under $<5$ years old. ${ }^{45}$ Because young children may have variable immune responses to $\mathrm{TB}$ infection, however, both tests should continue to be evaluated for diagnostic sensitivity. ${ }^{43,45}$ Finally, the borderline zone as well as the "wobble" phenomenon at the cutoff value should be further evaluated for clinical decision making. This may reduce the number of patients, especially health care workers, who are managed with preventive LTBI therapy. ${ }^{53-55}$

\section{Treatment of Latent Tuberculosis Infection (LTBI)}

After active TB disease has been excluded by clinical and laboratory evaluation, any patient diagnosed with LTBI should be considered for LTBI treatment, which reduces the risk of TB reactivation. Patients may encounter challenges in adhering to LTBI treatment, including limited access to health services, disease-related stigma, or minimal family or social support. ${ }^{10}$ LTBI treatment is completed when the patient has taken the appropriate quantity of pharmacologic doses. ${ }^{56}$ Two of the 3 medications of choice-isoniazid (INH) and rifampin (RIF) - have opposing mechanisms of action on cytochrome P450 enzymes (the former inhibits and the latter induces these enzymes), so patients with multipharmacologic regimens should be closely monitored. ${ }^{57}$ Dosages for pharmaceutical management recommended by the $\mathrm{CDC}^{58}$ are presented in Table 3.

As the medication of choice, INH should be prescribed daily for a total of 9 months in HIV-negative and HIV-positive children and adults, whether daily as self-administered therapy or biweekly as directly observed therapy (DOT). ${ }^{58-60}$ However, INH prescribed for a total of 6 months, whether a daily or biweekly regimen, is an appropriate alternative in HIV-negative children and adults. ${ }^{58-60}$ The American Academy of Pediatrics recommends 9 months of $\mathrm{INH}$ for children. ${ }^{58}$ Although delaying the INH treatment regimen is preferred after delivery in pregnant women, it may be administered if there is high risk for disease progression, such as documented recent close contact with an active case or immunosuppression. ${ }^{61}$ Adverse effects may include hepatic toxicity; therefore, physicians should discuss avoiding alcohol and promote adherence to the treatment regimen. $^{62}$ Baseline hepatic enzyme levels should be evaluated for individuals with HIV or underlying liver disease or pregnant or postpartum women; INH therapy should be routinely clinically monitored in patients with abnormal baseline results, including symptomatology related to liver inflammation, and liver function tests. ${ }^{58,63}$ Children should be monitored for symptomatology of hepatotoxicity rather than by routine laboratory evaluation. An additional adverse effect is peripheral neuropathy, which may be prevented by recommended pyridoxine (vitamin $\mathrm{B}_{6}$ ) supplementation. ${ }^{64}$ Other adverse reactions include dermatitis or lupus-like syndrome. ${ }^{57}$

As an alternative medication, RIF should be prescribed daily for a total of 4 months for HIVnegative patients who are intolerant to INH, have suspected hepatic toxicity, or have resistance to INH. ${ }^{58-60}$ Adverse effects include orange discoloration of body fluids, gastrointestinal disturbances, hypersensitivity reactions, and elevated hepatic enzymes. ${ }^{65}$ Recent research studies demonstrated that patients taking RIF for 4 months had reduced adverse side effects and increased compliance to completion of recommended treatment compared with those on 9 months of INH. ${ }^{66,67}$

However, a third therapeutic strategy has recently received greater attention when compared with the recommended 9 months of INH and the alternative 4 months of RIF. The 12-dose regimen of INH and rifapentine (RPT), or a once weekly 
Table 3. Pharmaceutical Management of Latent Tuberculosis Infection ${ }^{58}$

\begin{tabular}{|c|c|c|c|c|}
\hline Medication & Duration & Dose & Frequency & Total Doses (n) \\
\hline \multirow[t]{12}{*}{ Isoniazid } & \multirow[t]{6}{*}{9 months } & Adults: $5 \mathrm{mg} / \mathrm{kg}$ & \multirow[t]{3}{*}{ Daily } & \multirow[t]{3}{*}{270} \\
\hline & & Children: $10-20 \mathrm{mg} / \mathrm{kg}^{*}$ & & \\
\hline & & Maximum dose: $300 \mathrm{mg}$ & & \\
\hline & & Adults: $15 \mathrm{mg} / \mathrm{kg}$ & \multirow[t]{3}{*}{ Twice weekly by DOT } & \multirow[t]{3}{*}{76} \\
\hline & & Children: $20-40 \mathrm{mg} / \mathrm{kg}^{*}$ & & \\
\hline & & Maximum dose: $900 \mathrm{mg}$ & & \\
\hline & \multirow[t]{6}{*}{6 months } & Adult: $5 \mathrm{mg} / \mathrm{kg}$ & \multirow[t]{3}{*}{ Daily } & \multirow[t]{3}{*}{180} \\
\hline & & Children: Not recommended & & \\
\hline & & Maximum dose: $300 \mathrm{mg}$ & & \\
\hline & & Adults: $15 \mathrm{mg} / \mathrm{kg}$ & \multirow[t]{3}{*}{ Twice weekly by DOT } & \multirow[t]{3}{*}{52} \\
\hline & & Children: Not recommended & & \\
\hline & & Maximum dose: $900 \mathrm{mg}$ & & \\
\hline \multirow{8}{*}{$\begin{array}{l}\text { Isoniazid and } \\
\text { rifapentine }\end{array}$} & \multirow[t]{8}{*}{3 months } & Adults and children $>12$ years: & \multirow[t]{8}{*}{ Once weekly by DOT } & \multirow[t]{8}{*}{12} \\
\hline & & $\begin{array}{l}\mathrm{INH}^{\dagger}: 15 \mathrm{mg} / \mathrm{kg} \text { rounded up to nearest } \\
50 \text { or } 100 \mathrm{mg} ; 900 \mathrm{mg} \text { maximum }\end{array}$ & & \\
\hline & & $\mathrm{RPT}^{\dagger}:$ & & \\
\hline & & $\bullet 10.0-14.0 \mathrm{~kg}: 300 \mathrm{mg}$ & & \\
\hline & & $\bullet 14.1-25.0 \mathrm{~kg}: 450 \mathrm{mg}$ & & \\
\hline & & $\bullet 25.1-32.0 \mathrm{~kg}: 600 \mathrm{mg}$ & & \\
\hline & & $\bullet 32.1-49.9 \mathrm{~kg}: 750 \mathrm{mg}$ & & \\
\hline & & $\bullet \geq 50 \mathrm{~kg}: 900 \mathrm{mg}$ maximum & & \\
\hline \multirow[t]{2}{*}{ Rifampin } & \multirow[t]{2}{*}{4 months } & Adult: $10 \mathrm{mg} / \mathrm{kg}^{\ddagger}$ & \multirow[t]{2}{*}{ Daily } & \multirow[t]{2}{*}{120} \\
\hline & & Maximum dose: $600 \mathrm{mg}$ & & \\
\hline
\end{tabular}

*The American Academy of Pediatrics recommended INH dosage.

${ }^{\dagger} \mathrm{INH}$ is formulated as 100- and 300-mg tablets. RPT is formulated as $150-\mathrm{mg}$ tablets in blister packs that should be kept sealed until use.

${ }^{\ddagger}$ In the United States, the recommended latent tuberculosis infection treatment in children is a 9-month INH regimen. For latent tuberculosis infection treatment in infants, children, and adolescents when INH cannot be tolerated or the child has had contact with a patient infected with an INH-resistant but rifamycin-susceptible organism, the American Academy of Pediatrics recommends a 6-month daily rifampin dosage (180 dosages) of 10 to $20 \mathrm{mg} / \mathrm{kg}$.

DOT, directly observed therapy; INH, isoniazid; RPT, rifapentine.

dose for 3 months, can be prescribed for HIVnegative patients $>12$ years old. ${ }^{58,68}$ Because RPT is a pharmacological derivative of RIF, clinical trials have demonstrated that although adverse effects are similar to monotherapy INH or RIF, there are fewer drug-drug interactions with RPT. ${ }^{63}$ One multicenter randomized clinical trial concluded that participants who followed this 12-dose regimen by DOT demonstrated increased compliance to treatment and equivalent therapeutic outcomes when compared with those taking INH monotherapy. ${ }^{69,70}$ Key diagnostic and treatment recommendations for practice according to the Strength of Recommendations Taxonomy are presented in Table $4 .^{71}$

\section{Conclusions}

Diagnostic measures that accurately identify LTBI in patients with increased risk for developing TB dis- ease, followed by the recommended pharmacologic regimen, is the main priority to decrease the incidence, prevalence, and mortality of $\mathrm{TB} .{ }^{4}$ However, the prevalence of LTBI and risk of reactivation to TB disease present multiple challenges, including coinfection with HIV, immunosuppression, substance abuse, immigration, and multidrug resistance. ${ }^{6}$ IGRAs can be an important diagnostic tool that focuses on those population groups who are at higher risk for progression to active TB disease, including people with prior BCG vaccination and hard-toreach groups. ${ }^{16,45}$ With targeted screening programs, the number of individuals who require treatment of LTBI should decrease. Take-home points for specific population groups to be tested for $\mathrm{LTBI}^{10,12,58}$ are presented in Table 5.

With limited pharmacological discoveries in the past 4 decades, the advent of new strategies for active $\mathrm{TB}$ disease is encouraging for $\mathrm{TB}$ prevention 
Table 4. Key Diagnostic and Treatment Recommendations for Practice According to the Strength of Recommendations Taxonomy ${ }^{71}$

\begin{tabular}{|c|c|c|}
\hline Clinical Recommendation & $\begin{array}{l}\text { Strength of } \\
\text { Recommendation* }\end{array}$ & References \\
\hline $\begin{array}{l}\text { Sequential 2-step tuberculin skin tests should be performed in people who require baseline } \\
\text { evaluations and have initial negative test results. }\end{array}$ & $\mathrm{C}$ & 21 \\
\hline $\begin{array}{l}\text { Tuberculin skin tests are preferred over interferon- } \gamma \text { release assays as the diagnostic tool } \\
\text { in children }<5 \text { years old. }\end{array}$ & $\mathrm{B}$ & 45 \\
\hline $\begin{array}{l}\text { Interferon- } \gamma \text { release assays should be administered in adults, including BCG-vaccinated } \\
\text { individuals or people with immunocompromising conditions. }\end{array}$ & A & $37,38,44$ \\
\hline $\begin{array}{l}\text { Interferon- } \gamma \text { release assays should be administered in hard-to-reach groups for prompt } \\
\text { identification and management of LTBI. }\end{array}$ & A & 42,45 \\
\hline $\begin{array}{l}\text { Baseline laboratory values of hepatic enzyme levels should be performed in patients with } \\
\text { HIV or underlying liver disease or in pregnant or postpartum women, in whom } \\
\text { abnormal results should be evaluated routinely during LTBI therapy. }\end{array}$ & B & 58 \\
\hline $\begin{array}{l}\text { Daily regimen of isoniazid for a duration of } 9 \text { months is the medication of choice for } \\
\text { LTBI in adults and children. }\end{array}$ & A & 58 \\
\hline $\begin{array}{l}\text { Equivalent therapeutic outcomes of a 12-dose regimen of isoniazid and rifapentine for a } \\
\text { duration of } 3 \text { months, when compared with the daily regimen of isoniazid for a duration } \\
\text { of } 9 \text { months, have demonstrated increased compliance. }\end{array}$ & A & 69,70 \\
\hline
\end{tabular}

*Strength of recommendations: $\mathrm{A}=$ consistent and good quality patient-oriented evidence; $\mathrm{B}=$ inconsistent or limited quality patient-oriented evidence; $\mathrm{C}=$ consensus, usual practice, opinion, disease-oriented evidence, and case series for studies of diagnosis, treatment, prevention, or screening.

BCG, bacillus Calmette-Guérin; HIV, human immunodeficiency virus; LTBI, latent tuberculosis infection.

and control. ${ }^{72}$ Current research trials are investigating the use of the 12-dose INH and RPT regimen by DOT in low-income countries with high TB prevalence, as well as the actual cost-effectiveness and safety of using new regimens in clinical practice. $^{70}$

Along with the scientific advancements in diagnostic measures and multipharmaceutical regimens based on the infectious etiology of LTBI, the influence of social determinants of health on LTBI transmission and prevention may be key to global control of LTBIs. ${ }^{73-76}$ By focusing on screening high-risk population groups for $\mathrm{TB}$ reactivation, individuals may be identified and educated about LTBIs and recommended treatment. ${ }^{77}$ Together with cost-effective diagnostic measures, educa-

Table 5. Take-Home Points on Specific Population Groups to Test for Latent Tuberculosis Infections (LTBIs)

\begin{tabular}{|c|c|c|}
\hline Categories & Population Groups & Description \\
\hline \multirow{3}{*}{$\begin{array}{l}\text { High risk of exposure or infection } \\
\text { with Mycobacterium } \\
\text { tuberculosis }{ }^{10,12,58}\end{array}$} & Close contact & $\begin{array}{l}\text { Children, adolescents, or adults with close contact with } \\
\text { high-risk adults }\end{array}$ \\
\hline & Congregated living conditions & $\begin{array}{l}\text { Employees or residents of long-term care facilities, } \\
\text { correctional facilities, homeless shelters }\end{array}$ \\
\hline & Foreign born & $\begin{array}{l}\text { People who moved from countries with a high burden of } \\
\text { TB to the United States ( }<5 \text { years })\end{array}$ \\
\hline \multirow[t]{4}{*}{$\begin{array}{l}\text { High risk of LTBI progression to } \\
\text { TB disease }{ }^{10,12,58}\end{array}$} & History of TB & $\begin{array}{l}\text { People acquiring latent TB infection within the previous } \\
2 \text { years or people with previous untreated/ineffective } \\
\text { treatment of active TB with no sign of active TB at } \\
\text { the time of starting latent TB treatment }\end{array}$ \\
\hline & Age & Children $<4$ years \\
\hline & Substance use & People who inject illicit drugs \\
\hline & Immunosuppression & $\begin{array}{l}\text { People with poor nutrition status; previous surgical } \\
\text { interventions (e.g., gastrointestinal surgical } \\
\text { procedures); immunosuppressive medications (e.g., } \\
\text { tumor necrosis factor- } \alpha \text { antagonists, chronic } \\
\text { corticosteroid use); immunocompromising conditions } \\
\text { (e.g., HIV, chronic renal failure, diabetes mellitus, } \\
\text { cancer) }\end{array}$ \\
\hline
\end{tabular}

HIV, human immunodeficiency virus; TB, tuberculosis. 
tional programs may facilitate patient understanding about LTBIs and the importance of compliance to pharmacological treatment, leading toward improved global control of LTBIs.

\section{References}

1. Glaziou P, Falzon D, Floyd K, Raviglione M. Global epidemiology of tuberculosis. Semin Respir Crit Care Med 2013;34:3-16.

2. Global tuberculosis report 2013. Geneva, Switzerland: World Health Organization; 2013.

3. Lawn SD, Zumla AI. Tuberculosis. Lancet 2011; 378:57-72.

4. Zumla A, Raviglione M, Hafner R, von Reyn CF. Tuberculosis. N Engl J Med 2013;368:745-55.

5. Frieden TR, Sterling TR, Munsiff SS, Watt CJ, Dye C. Tuberculosis. Lancet 2003;362:887-99.

6. Millet JP, Moreno A, Fina L, et al. Factors that influence current tuberculosis epidemiology. Eur Spine J 2013;22(Suppl 4):539-48.

7. Gordin FM, Masur H. Current approaches to tuberculosis in the United States. JAMA 2012;308:283-9.

8. Barker RD. Clinical tuberculosis. Medicine 2008;36: 300-5.

9. Fact sheet: trends in tuberculosis, 2012. Atlanta, GA: Centers for Disease Control and Prevention (CDC); 2013. Available from: http://www.cdc.gov/tb/publications/ factsheets/statistics/TBTrends.htm. Accessed July 20, 2014.

10. Inge LD, Wilson JW. Update on the treatment of tuberculosis. Am Fam Physician 2008;78:457-65, 469-70.

11. ATS. Diagnostic standards and classification of tuberculosis in adults and children. Joint statement of the American Thoracic Society and the Centers for Disease Control and Prevention, July 1999. Endorsed by the Council of the Infectious Disease Society of America, September 1999. Am J Respir Crit Care Med 2000;161(4 Pt 1):1376-95.

12. Hauck FR, Neese BH, Panchal AS, El-Amin W. Identification and management of latent tuberculosis infection. Am Fam Physician 2009;79:879-86.

13. Taylor Z, Nolan CM, Blumberg HM; American Thoracic Society; Centers for Disease Control and Prevention; Infectious Diseases Society of America. Controlling tuberculosis in the United States. Recommendations from the American Thoracic Society, Centers for Disease Control and Prevention, and the Infectious Diseases Society of America. MMWR Recomm Rep 2005;54(RR-12):1-81.

14. Centers for Disease Control and Prevention (CDC). Trends in tuberculosis-United States, 2007. MMWR Morb Mortal Wkly Rep 2008;57:281-5.

15. Centers for Disease Control and Prevention (CDC). Trends in tuberculosis-United States, 2012. MMWR Morb Mortal Wkly Rep 2013;62:201-5.
16. Horsburgh CR Jr, Rubin EJ. Clinical practice. Latent tuberculosis infection in the United States. N Eng J Med 2011;364:1441-8.

17. Schwartzman K. Latest tuberculosis infection: old problem, new priorities. CMAJ 2002;166:759-61.

18. Shea KM, Kammerer JS, Winston CA, Navin TR, Horsburgh CR Jr. Estimated rate of reactivation of latent tuberculosis infection in the United States, overall and by population subgroup. Am J Epidemiol 2014;179:216-25.

19. Andersen P, Doherty TM, Pai M, Weldingh K. The prognosis of latent tuberculosis: can disease be predicted? Trends Mol Med 2007;13:175-82.

20. Campos-Outcalt D. Tuberculosis: old problem, new concerns. J Fam Pract 2003;52:792-8.

21. Trajman A, Steffen RE, Menzies D. Interferongamma release assays versus tuberculin skin testing for the diagnosis of latent tuberculosis infection: an overview of the evidence. Pulm Med 2013;2013: 601737.

22. Madariaga MG, Jalali Z, Swindells S. Clinical utility of interferon gamma assay in the diagnosis of tuberculosis. J Am Board Fam Med 2007;20:540-7.

23. Schluger NW. Advances in the diagnostics of latent tuberculosis infection. Semin Respir Crit Care Med 2013;34:60-6.

24. Hwang LY, Grimes CZ, Beasley RP, Graviss EA. Latent tuberculosis infections in hard-to-reach drug using population-detection, prevention and control. Tuberculosis (Edinb) 2009;89(Suppl 1):S41-5.

25. Andersen P, Munk ME, Pollock JM, Doherty TM. Specific immune-based diagnosis of tuberculosis. Lancet 2000;356:1099-104.

26. Abubakar I, Stagg HR, Whitworth H, Lalvani A. How should I interpret an interferon gamma release assay result for tuberculosis infection? Thorax 2013; 68:298-301.

27. Mazurek GH, Villarino ME; Division of Tuberculosis Elimination; National Center for HIV, STD, and TB Prevention; Centers for Disease Control and Prevention. Guidelines for using the QuantiFERON@-TB test for diagnosing latent Mycobacterium tuberculosis infection. MMWR Morb Mortal Wkly Rep 2003; 52(RR-02):15-8.

28. Mazurek GH, Jereb J, Lobue P, Iademarco MF, Metchock B, Vernon A; Division of Tuberculosis Elimination; National Center for HIV, STD, and TB Prevention; Centers for Disease Control and Prevention. Guidelines for using the QuantiFERON®-TB Gold test for detecting Mycobacterium tuberculosis infection, United States. MMWR Recomm Rep 2005;54(RR-15):49-55.

29. Simpson T, Fox J, Crouse K, Field K. Screening for Mycobacterium tuberculosis using an interferongamma release assay. J Public Health Manag Pract 2012;18:E19-25. 
30. Pollock L, Basu Roy R, Kampmann B. How to use: interferon gamma release assays for tuberculosis. Arch Dis Child Educ Pract Ed 2013;98:99-105.

31. Lavlani A. Diagnosing tuberculosis infection in the 21st century: new tools to tackle an old enemy. Chest 2007;131:1898-906.

32. Pai M, Kalantri S, Dheda K. New tools and emerging technologies for the diagnosis of tuberculosis: part I. Latent tuberculosis. Expert Rev Mol Diagn 2006;6:413-22.

33. Linas BP, Wong AY, Freedberg KA, Horsburgh CR Jr. Priorities for screening and treatment of latent tuberculosis infection in the United States. Am J Respir Crit Care Med 2011;184:590-601.

34. Reported tuberculosis in the United States, 2012. Atlanta, GA: Centers for Disease Control and Prevention (CDC), U.S. Department of Health and Human Services; 2013.

35. Triverio PA, Bridevauz PO, Roux-Lombard P, et al. Interferon-gamma release assays versus tuberculin skin testing for detection of latent tuberculosis in chronic haemodialysis patients. Nephrol Dial Transplant 2009;24:1952-6.

36. Winthrop KL. Weinblatt ME, Daley CL. You can't always get what you want, but if you try sometimes (with two tests-TST and IGRA-for tuberculosis) you get what you need. Ann Rheum Dis 2012;71: 1757-60.

37. Diel R, Loddenkemper R, Nienhaus A. Evidencebased comparison of commercial interferon- $\gamma$ release assays for detecting active TB: a metaanalysis. Chest 2010;137:952-68.

38. Diel R, Goletti D, Ferrara G, et al. Interferon- $\gamma$ release assays for the diagnosis of latent Mycobacterium tuberculosis infection: a systematic review and meta-analysis. Eur Respir J 2011;37:88-99.

39. Pai M, Riley LW, Colford JM Jr. Interferon-gamma assays in the immunodiagnosis of tuberculosis: a systematic review. Lancet Infect Dis 2004;4:761-76.

40. Pinto LM, Grenier J, Schumacher SG, Denkinger CM, Steingart KR, Pai M. Immunodiagnosis of tuberculosis: state of the art. Med Princ Pract 2012;21: 4-13.

41. Chiapphi E, Fossi F, Bonsignori F, Sollai S, Galli L, de Martino M. Utility of interferon-gamma release assay results to monitor anti-tubercular treatment in adults and children. Clin Ther 2012;34:1041-8.

42. National Collaborating Centre for Chronic Conditions. Tuberculosis. Clinical diagnosis and management of tuberculosis, and measures for its prevention and control. Clinical guideline no. 117. London: National Institute for Health and Clinical Excellence (NICE); 2011.

43. Mandalakas AM, Detjen AK, Hesseling AC, Benedetti A, Menzies D. Interferon-gamma release assays and childhood tuberculosis: systematic review and metaanalysis. Int J Tuberc Lung Dis 2011;15:1018-32.
44. Grant J, Jastrzebski J, Johnston J, et al. Interferongamma release assays are a better tuberculosis screening test for hemodialysis patients: a study and review of the literature. Can J Infect Dis Med Microbiol 2012;23:114-6.

45. Mazurek GH, Jereb J, Vernon A, LoBue P, Goldberg S, Castro K; IGRA Expert Committee; Centers for Disease Control and Prevention. Updated guidelines for using interferon gamma release assays to detect Mycobacterium tuberculosis infection-United States, 2010. MMWR Recomm Rep 2010;58(RR-5): $1-25$.

46. Starke JR. Interferon- $\gamma$ release assays for the diagnosis of tuberculosis infection in children. J Pediatr 2012;161:581-2.

47. van Zyl-Smit RN, Pai M, Peprah K, et al. Withinsubject variability and boosting of $\mathrm{T}$-cell interferon$\gamma$ responses after tuberculin skin testing. Am J Respir Crit Care Med 2009;180:49-58.

48. Ringshausen FC, Nienhaus A, Torres Costa J, et al. Within-subject variability of Mycobacterium tuberculosis-specific gamma interferon responses in German health care workers. Clin Vaccine Immunol 2011;18:1176-82.

49. Tsai KS, Chang HL, Chien ST, et al. Childhood tuberculosis: epidemiology, diagnosis, treatment, and vaccination. Pediatr Neonatol 2013;54:295-302.

50. Takenami I, Loureiro C, Machado A Jr, Emodi K, Riley LW, Arruda S. Blood cells and interferongamma levels correlation in latent tuberculosis infection. ISRN Pulmonol 2013;2013. pii:256148.

51. Sridhar S, Pollock K, Lalvani A. Redefining latent tuberculosis. Future Microbiol 2011;6:1021-35.

52. Smith R, Cattamanchi A, Steingart KR, et al. Interferon-gamma release assays for diagnosis of latent tuberculosis infection: evidence in immune-mediated inflammatory disorders. Curr Opin Rheumatol 2011;23:377-84.

53. Alexander TS, Miller MB, Gilligan P. Should interferon gamma release assays become the standard method for screening patients for Mycobacterium tuberculosis infections in the United States. J Clin Microbiol 2011;49:2086-92.

54. Metcalfe JZ, Cattamanchi A, McCulloch CE, Lew JD, Ha NP, Graviss EA. Test variability of the QuantiFERON-TB Gold In-Tube assay in clinical practice. Am J Resp Crit Care Med 2013;187: 206-11.

55. Nienhaus A, Ringshausen FC, Costa JT, Schablon A, Tripodi D. IFN- $\gamma$ release assay versus tuberculin skin test for monitoring TB infection in healthcare workers. Expert Rev Anti Infect Ther 2013;11:3748.

56. Targeted tuberculin testing and treatment of latent tuberculosis infection. American Thoracic Society. MMWR Recomm Rep 2000;49(RR-6):1-54.

57. Vernon A. Treatment of latent tuberculosis infection. Semin Respir Crit Care Med 2013;34:67-86. 
58. Latent tuberculosis infection: a guide for primary health care providers. Atlanta, GA: Centers for Disease Control and Prevention, U.S. Department of Health and Human Services; 2013. Available from: http://www.cdc.gov/tb/publications/ltbi/default.htm. Accessed July 20, 2014.

59. Blumberg HM, Leonard MK Jr, Jasmer RM. Update on the treatment of tuberculosis and latent tuberculosis infection. JAMA 2005;293:2776-84.

60. Lobue P, Menzies D. Treatment of latent tuberculosis infection: an update. Respirology 2010;15: 603-22.

61. Denholm JT, McBryde ES. The use of anti-tuberculosis therapy for latent TB infection. Infect Drug Resist 2010;3:63-72.

62. Isoniazid. Tuberculosis (Edinb) 2008;88:112-6.

63. Parekh M, Schluger N. Treatment of latent tuberculosis infection. Ther Adv Respir Dis 2013;7: 351-6.

64. Ahmad S. New approaches in the diagnosis and treatment of latent tuberculosis infection. Respir Res 2010;11:169.

65. Rifampin. Tuberculosis (Edinb) 2008;88:151-4.

66. Page KR, Sifakis F, Montes de Oca R, et al. Improved adherence and less toxicity with rifampin vs isoniazid for treatment of latent tuberculosis. Arch Intern Med 2006;166:1863-70.

67. Esfahani K, Aspler A, Menzies D, Schwartzman K. Potential cost-effectiveness of rifampin vs isoniazid for latent tuberculosis: implications for future clinical trials. Int J Tuberc Lung Dis 2011;15:1340-6.

68. Centers for Disease Control and Prevention (CDC). Recommendations for use of an isoniazid-rifapentine regimen with direct observation to treat latent Mycobacterium tuberculosis infection. MMWR Morb Mortal Wkly Rep 2011;60:1650-3.
69. Sterling TR, Villarino ME, Borisov AS, et al. TB Trials Consortium PREVENT TB Study Team. Three months of rifapentine and isoniazid for latent tuberculosis infection. N Engl J Med 2011;365: 2155-66.

70. Sharma SK, Sharma A, Kadhiravan T, Tharyan P. Rifamycins (rifampicin, rifabutin and rifapentine) compared to isoniazid for preventing tuberculosis in HIV-negative people at risk of active TB. Cochrane Database Syst Rev 2013;7:CD007545.

71. Ebell MH, Siwek J, Weiss BD, et al. Strength of recommendation taxonomy (SORT): a patient-centered approach to grading evidence in the medical literature. J Am Board Fam Pract 2004;17:59-67.

72. Dooley KE, Nuermberger EL, Diacon AH. Pipeline of drugs for related diseases: tuberculosis. Curr Opin HIV AIDS 2013;8:579-85.

73. Ho MJ. Sociocultural aspects of tuberculosis: a literature review and a case study of immigrant tuberculosis. Soc Sci Med 2004;59:753-62.

74. Lönnroth K, Jaramillo E, Williams BG, Dye C, Raviglione M. Drivers of tuberculosis epidemics: the role of risk factors and social determinants. Soc Sci Med 2009;68:2240-6.

75. Hargreaves JR, Boccia D, Evans CA, Adato M, Petticrew M, Porter JD. The social determinants of tuberculosis: from evidence to action. Am J Pub Health 2011;101:654-62.

76. Bates I, Fenton C, Gruber J, et al. Vulnerability to malaria, tuberculosis, and HIV/AIDS infection and disease. Part 1: determinants operating at individual and household level. Lancet Infect Dis 2004;4: 267-77.

77. Colson PW, Hirsch-Moverman Y, Bethel J, et al. Tuberculosis Epidemiologic Studies Consortium. Acceptance of treatment for latent tuberculosis infection: prospective cohort study in the United States and Canada. Int J Tuberc Lung Dis 2013;17: 473-9. 